\title{
AVALIAÇÃO SENSORIAL DO CAFÉ CEREJA DESCASCADO, ARMAZENADO SOB ATMOSFERA ARTIFICIAL E CONVENCIONAL
}

\author{
Sensorial evaluation of shelled cherry-colored type coffee stored \\ under artificial and conventional atmosphere
}

\author{
Flávio Meira Borém ${ }^{1}$, Gilberto Westin Nobre ${ }^{2}$, Simone Miranda Fernandes ${ }^{3}$, \\ Rosemary Gualberto F. A. Pereira ${ }^{4}$, Pedro Damasceno de Oliveira ${ }^{5}$
}

\begin{abstract}
RESUMO
Objetivou-se, com o presente trabalho, avaliar sensorialmente as bebidas e classificar quanto ao tipo o café cereja descascado submetido a diferentes acondicionamentos, ao longo do armazenamento. $\mathrm{O}$ experimento foi instalado em delineamento inteiramente casualizado (DIC), em esquema fatorial 2x5x5, com três repetições. Foram testados cinco acondicionamentos, com e sem modificação de atmosfera, em cinco épocas de avaliação, em dois lotes de café cereja descascado, sendo um em pergaminho e o outro beneficiado. Os acondicionamentos em embalagens impermeáveis (sacos de náilon, sacos de náilon com $40 \%$ de $\mathrm{CO}_{2}$ e sacos aluminizados a vácuo) apresentaram capacidade de preservar a qualidade de bebida do café cereja descascado, na duração e nas condições do experimento. Os cafés acondicionados em embalagens permeáveis (sacos de juta e sacos de juta com casca de café picada) apresentaram alterações sensoriais que depreciaram a qualidade do café. Na classificação física, o tipo do café não sofreu alteração nos diversos acondicionamentos usados durante o experimento.
\end{abstract}

Termos para indexação: Café, cereja descascado, armazenamento, qualidade, Coffea arabica L.

\section{ABSTRACT}

The present work aimed to give a sensorial evaluation to the coffee (Coffea arabica L.) beverage and to classify the shelled cherry-colored type coffee submitted to different packaging during storage. The experiment was installed entirely at random in a factorial outline $2 \times 5 \times 5$, with three repetitions. Five packages were tested, with and without atmosphere modification, in five evaluation times, in two lots of shelled cherry-colored coffee, with one dried and the other processed. The impermeable packages (nylon sacks, nylon sacks with $40 \%$ of $\mathrm{CO}_{2}$ and foil vacuum packs) presented a capacity of preserving the quality of the drink of the shelled cherry-colored coffee, throughout the duration and conditions of the experiment. The coffee conditioned in permeable packing (jute sacks and jute sacks with ground coffee shells) presented sensorial alterations that depreciated the quality of the coffee. In the physical classification, the type of coffee didn't suffer alteration in the several packages used during the experiment.

Index terms: Coffee, parchment coffee, storage, quality, Coffea arabica $\mathrm{L}$.

(Recebido em 21 de dezembro de 2006 e aprovado em 12 de junho de 2007)

\section{INTRODUÇÃo}

O armazenamento é uma prática obrigatória na cadeia produtiva e todo café preparado para o consumo requer, nas fases da pós-colheita, obrigatoriamente, o armazenamento do produto. O mercado mundial de café tem premiado cafés com elevado padrão de qualidade, sendo o segmento dos cafés especiais o que apresenta maior crescimento nos últimos anos.
Entre os diversos fatores que contribuem para a obtenção de cafés com qualidade, as etapas pós-colheita possuem grande influência na determinação dos atributos sensoriais do café, especialmente a forma de processamento e secagem. Sabe-se que o processamento por via seca ou via úmida resultam com cafés com diferentes características no sabor e no aroma bem como no corpo, acidez e doçura do café. Considerando o conjunto de atributos físicos e sensoriais, o café cereja

\footnotetext{
'Doutor, Professor Associado - Departamento de Engenharia/DEG - Universidade Federal de Lavras/UFLA - Cx. P. 3037 - $37200-000$ - Lavras, MGflavioborem@ufla.br

${ }^{2}$ Doutorando - Departamento de Agricultura/DAG - Universidade Federal de Lavras/UFLA - Cx. P. 3037 - $37200-000$ - Lavras, MG -

gilbertonobre@navinet.com.br Bolsista FAPEMIG

${ }^{4}$ Doutora, Professora Adjunto - Departamento de Ciência dos Alimentos/DCA - Universidade Federal de Lavras/UFLA - Cx. P. 3037 - $37200-000$ Lavras, MG - rosegfap@ufla.br

${ }^{5}$ Graduando - Departamento de Engenharia/DEG - Universidade Federal de Lavras/UFLA - Cx. P. 3037 - $37200-000$ - Lavras, MG damascenoeng@yahoo.com.br
} 
descascado vem se destacando em termos mercadológicos. Entretanto, há que se prolongar o tempo de armazenamento para que o cafeicultor possa ofertar seu produto por maior período buscando atingir o mercado nos períodos mais favoráveis.

No entanto, dependendo das condições de armazenamento, o café tem suas características iniciais alteradas, ocorrendo transformações físicas, químicas, bioquímicas e sensoriais (COELHO et al., 2001; GODINHO et al., 2000; LOPES et al. 2000; VILELA et al., 2000) que poderão comprometer sua comercialização como cafés especiais. Também, Alves et al. (2003) avaliando a qualidade de grãos de café durante o armazenamento em condições diversas, verificaram queda de qualidade de bebida nos grãos de café com o aumento da temperatura e do tempo de armazenamento.

Somente com a preservação da sua qualidade, durante o armazenamento, é que será possível obter preço compatível e remunerador para o produto.

Técnicas de armazenamento do café com acondicionamento sob atmosfera artificial têm potencial para garantir preservação da qualidade, num armazenamento mais prolongado e oferecer, ainda, melhoria na aparência e diferenciação do produto. Algumas empresas brasileiras de produção e exportação de café já vêm usando o acondicionamento hipobárico com sucesso. Entretanto, essa forma de acondicionamento possui elevado custo não sendo viável para diversos outros produtores. Nesse contexto, faz-se necessário o desenvolvimento de novas técnicas que permitam aumentar o tempo de armazenamento, com a preservação da qualidade do café cereja com custo acessível a um maior número de produtores.

A atmosfera artificial é, hoje, uma técnica largamente utilizada no armazenamento e transporte de diversos produtos agrícolas. Seu princípio de funcionamento baseiase na modificação da concentração de gases na atmosfera natural. Dessa forma, os produtos armazenados com atmosfera artificial apresentarão uma drástica redução nos processos metabólicos e, conseqüentemente, a manutenção de suas características iniciais por períodos mais prolongados.

Segundo Dilley (1977), a temperatura, a umidade relativa e a concentração de certos gases podem ser alteradas empregando-se atmosfera controlada, atmosfera modificada, atmosfera hipobárica, filmes plásticos semipermeáveis e geração de gases inertes.

Rossignoli (1983) afirma que o termo "atmosfera modificada" é usado para designar a atmosfera formada em recipiente hermeticamente fechado, sem o controle das concentrações de gases. Na atmosfera controlada, as concentrações de $\mathrm{CO}_{2}, \mathrm{~N}_{2}$ e $\mathrm{O}_{2}$ são mantidas constantes e em níveis diferentes das da atmosfera normal. Já na atmosfera hipobárica, a pressão parcial de $\mathrm{O}_{2}$ é reduzida empregando-se vácuo parcial nas embalagens.

Segundo Penteado (1998), os poliolefínicos, como o polietileno, o polipropileno e o polibutileno, assim como seus copolímeros apresentam, em geral, boa barreira ao vapor d'água, alta permeabilidade aos gases e favorável resposta à selagem a quente.

Segundo Moura (1997), os produtos apresentam uma ampla variedade de respostas às alterações nas concentrações de $\mathrm{O}_{2}$ e $\mathrm{CO}_{2}$, e, por essa razão, combinações ideais precisam ser determinadas, experimentalmente, para cada produto.

Hardemburg, citado por Rossignoli (1983), considera que os filmes de polietileno são mais permeáveis ao $\mathrm{CO}_{2}$ do que ao $\mathrm{O}_{2}$, e que o acúmulo de $\mathrm{CO}_{2}$, por conseguinte, é menor do que a taxa de depleção de $\mathrm{O}_{2}$ correspondente. $\mathrm{O}$ náilon (PA - poliamida) é outro material usado para embalagens com propriedades muito boas com relação à impermeabilidade ao oxigênio (cerca de 60 vezes a do polietileno), mas apresenta maior permeabilidade à umidade (CEREDA, 1983).

$\mathrm{O}$ armazenamento hipobárico também é um método de modificação de atmosfera, para Chitarra \& Chitarra (1990) e corresponde ao armazenamento sob vácuo parcial. Tem como principais méritos: a remoção de diversos gases e outros voláteis, o abaixamento da pressão parcial de $\mathrm{O}_{2}$ a níveis mais baixos do que os conseguidos com controle atmosférico e, como conseqüência, a redução das atividades metabólicas do produto.

Para Rosset, citado por Passos (1991), o objetivo do processo a vácuo é manter um volume mínimo de ar dentro da embalagem durante o armazenamento. A redução do fornecimento de $\mathrm{O}_{2}$ reduz a taxa de respiração e o metabolismo do produto, minimizando as alterações que ocorrem durante o armazenamento.

Entretanto, segundo Hardemburg, citado por Penteado (1998), grãos armazenados em embalagens hermeticamente fechadas e a vácuo deverão apresentar baixo conteúdo de água e, portanto, baixa atividade metabólica.

Objetivou-se, no presente trabalho, avaliar, sensorialmente, as bebidas e classificar quanto ao tipo o café cereja descascado (Coffea arabica L.) submetido a diferentes acondicionamentos, ao longo do armazenamento.

\section{MATERIAL E MÉTODOS}

O café foi processado por via úmida e após o descascamento foi secado em terreiro de cimento e armazenado, temporariamente, em tulha de madeira no Pólo 
de Tecnologia e Pós-Colheita do Café da Universidade Federal de Lavras. Posteriormente $300 \mathrm{~kg}$ de café cereja descascado foram beneficiados e outros $300 \mathrm{~kg}$ foram mantidos com o pergaminho. $\mathrm{O}$ experimento foi instalado em delineamento inteiramente casualizado (DIC), em esquema fatorial $2 \times 5 \times 5$, com três repetições, sendo dois níveis de preparo (com pergaminho e beneficiado), cinco tipos de acondicionamento (sacos de juta, sacos de juta casca de café moída, sacos de náilon com $40 \%$ de $\mathrm{CO}_{2}$, sacos de náilon e embalagens de aluminizadas a vácuo) e cinco épocas de avaliação. As análises foram realizadas nos tempos: zero, 90, 180, 270 e 360 dias. As parcelas foram constituídas por $3 \mathrm{~kg}$ de café. Os cafés foram armazenados num estrado, a um metro do piso, em blocos contíguos constituídos de todos os tratamentos usados, no armazém do Pólo de Tecnologia em Pós-Colheita do Café, onde permaneceram durante 360 dias. $\mathrm{O}$ estrado contendo o experimento foi cercado por uma pilha de sacos de café em coco, de 2 metros de altura, em forma de $\mathrm{U}$, de tal forma que ficasse posicionado dentro da pilha - que apresentava um pequeno corredor de acesso. Com isso simularam-se as condições, mais próximas possíveis, de um armazenamento real. Nas parcelas com acondicionamento em atmosfera modificada usaram-se sacos aluminizados multifoliados, próprios para embalar, a vácuo, café torrado e moído e embalagens multicamadas de náilon (PA) e polietileno, com excelentes características de soldadura e impermeabilidade a gazes. Os acondicionamentos permeáveis, que simularam as condições usuais de armazenamento, foram confeccionados a partir de sacos de juta, próprios para café, redimensionados nas medidas de 30x60 cm. Para o tratamento em sacas de juta com casca moída de café, foi utilizada palha de café retirada do palheiro, que foi triturada no moinho a martelo, em partículas menores que $0,7 \mathrm{~cm}$. Essa casca de café moída foi misturada com os cafés na proporção (em volume) de uma parte e meia para cada parte de café. A avaliação sensorial foi realizada por provador do Ministério da Agricultura, sendo que a primeira foi feita imediatamente no início da armazenagem e as demais com intervalo de 90 dias e computadas na forma de freqüência.

Tanto a classificação física do café quanto a prova de xícara (ponto de torra americana) para avaliar a qualidade de sua bebida foi realizada de acordo com a Instrução Normativa $n^{0} 8$. Na prova de xícara também foram avaliados os atributos doçura, acidez e corpo em três níveis de percepção.

\section{RESULTADOS E DISCUSSÃO}

Pela Figura 1, observou-se que o café acondicionado em café náilon $+\mathrm{CO}_{2}$ apresentou maior frequiência de bebida mole, seguido dos cafés acondicionados a vácuo. A maior freqüência de bebida dura foi verificada nos cafés condicionados em sacos de juta e sacos de juta com casca picada. Pela Figura 2, nota-se que o café com pergaminho apresentou a maior frequiência de bebida apenas mole, enquanto que no café beneficiado predominou a freqüência de bebida dura. A presença do pergaminho inibiu a alteração da qualidade, como se pode constatar com uma frequiência cinco vezes maior de café duro nos cafés beneficiados em relação ao ocorrido com os cafés com pergaminho. A freqüência da bebida estritamente mole foi maior no início do experimento.

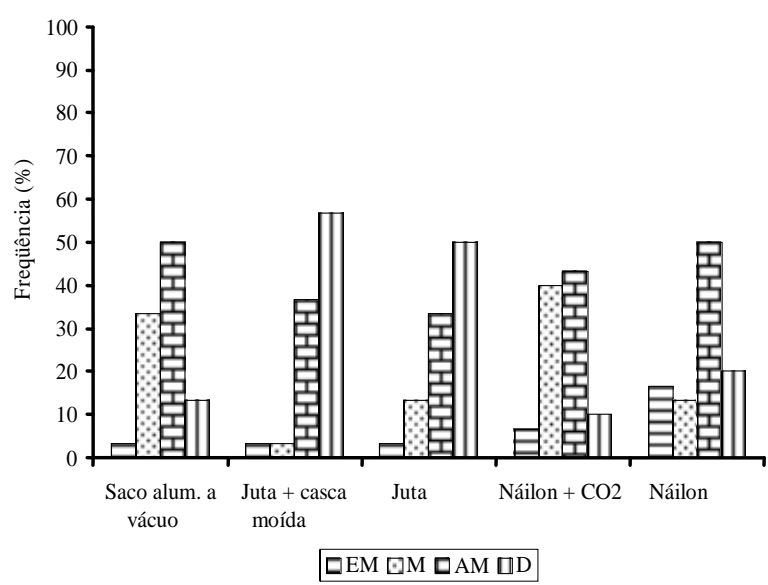

Figura 1 - Frequiência para as bebidas dos cafés com pergaminho e beneficiado em diferentes tipos de acondicionamentos.

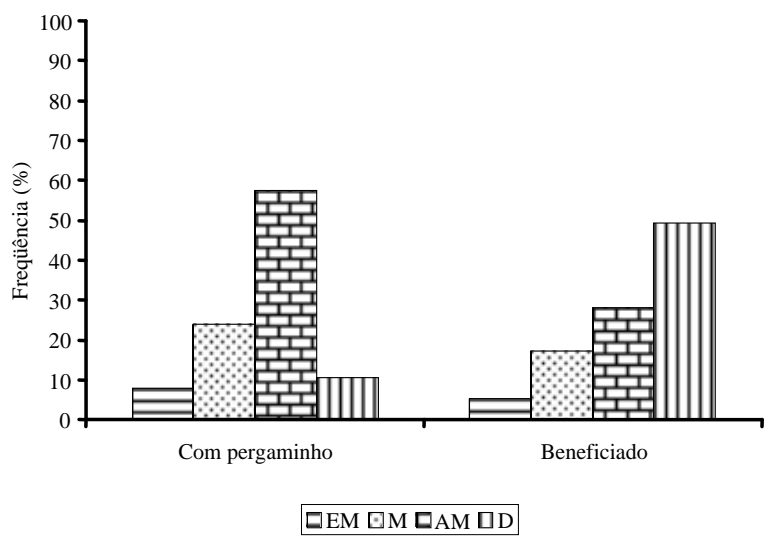

Figura 2 - Freqüência para bebida dos cafés com pergaminho e beneficiado.

Observa-se pela Tabela 1 que houve perda de qualidade nos cafés com tipos de acondicionamentos. Os 
cafés com pergaminho e beneficiados, acondicionados em sacos de juta e sacos de juta com casca de café moída, a partir dos 180 dias de armazenamento, com a qualidade de bebida passando de mole e apenas mole, (predominantes aos 90 dias) para a bebida dura. Nos demais acondicionamentos em embalagens impermeáveis, houve tendência de manter a bebida predominantemente apenas mole, do início até o final do experimento, ressaltando a capacidade de preservação da qualidade de bebida do café desses acondicionamentos.

A avaliação do atributo doçura, encontra-se apresentado em forma de freqüência, para os diferentes tipos de acondicionamentos na Figura 3.

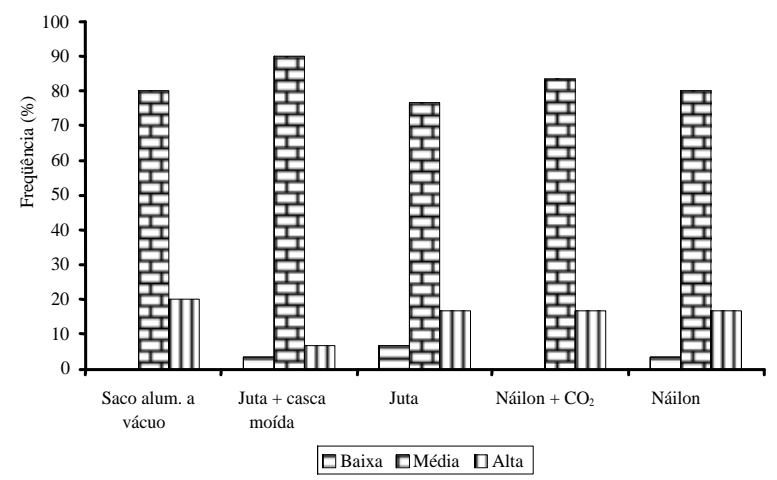

Figura 3 - Freqüência para o atributo doçura, para os cafés com pergaminho em diferentes tipos de acondicionamentos.

Verifica-se, pelo gráfico da Figura 3, que o atributo doçura média predominou, com ligeiras oscilações entre os tipos de acondicionamento estudados. Observa-se que não ocorreu o atributo doçura baixa no café acondicionado em sacos de náilon com $\mathrm{CO}_{2}$ e a vácuo.

A avaliação do atributo acidez observa-se apresentado em forma de freqüência para os diferentes tipos de acondicionamentos, na Figura 4.

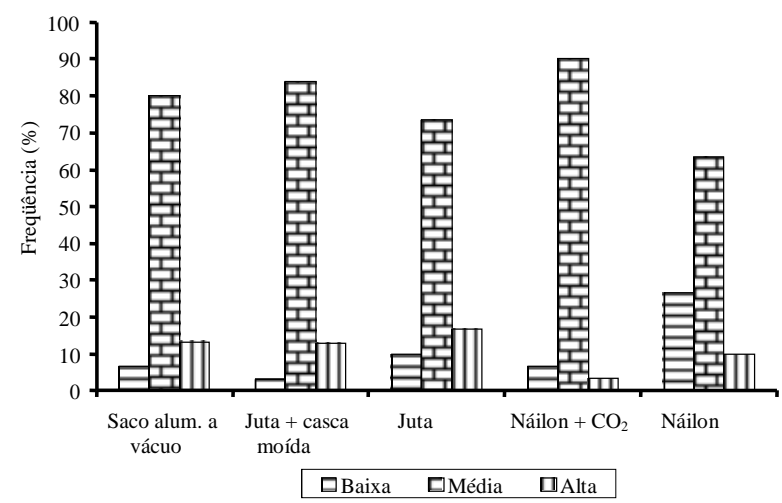

Figura 4 - Frequiência para o atributo acidez, para os cafés com pergaminho e beneficiado em diferentes de acondicionamentos.

$\mathrm{O}$ atributo acidez média foi predominante em todos os acondicionamentos durante o armazenamento, nos diversos cafés estudados.

Destaca-se que a maior frequiência para o atributo da acidez baixa foi verificada nos cafés acondicionados em sacos de náilon, nos dois níveis de beneficiamento, durante o armazenamento, nos diversos cafés estudados.

Durante a duração do experimento verificou-se maior freqüência da acidez alta, nos cafés com

Tabela 1 - Prova de xícara para o café beneficiado e com pergaminho submetido a diferentes acondicionamentos, durante 360 dias de armazenamento.

\begin{tabular}{lcccccc}
\hline \multirow{2}{*}{$\begin{array}{c}\text { Modo de } \\
\text { acondicionamento }\end{array}$} & Beneficiamento & 0 & 90 & 180 & 270 & 360 \\
\hline \multirow{2}{*}{ Juta } & Com & AM & M & D & D & D \\
& Sem & AM & AM & D & D & D \\
\hline \multirow{2}{*}{ Juta com casca moída } & Com & AM & AM & D & D & D \\
& Sem & AM & AM & D & D & D \\
\hline \multirow{2}{*}{ Náilon } & Com & AM & AM & D & AM & AM \\
& Sem & EM & AM & AM & EM & AM \\
\hline \multirow{2}{*}{ Náilon com $\mathrm{CO}_{2}$} & Com & AM & M & AM & AM & M \\
& Sem & M & AM & D & EM & M \\
\hline \multirow{2}{*}{ A vácuo } & Com & M & AM & AM & D & AM \\
& Sem & AM & M & AM & AM & M \\
\hline
\end{tabular}

$\mathrm{EM}=$ Estritamente Mole; $\mathrm{M}=$ Mole; $\mathrm{AM}=$ Apenas Mole; $\mathrm{D}=$ Dura . 
pergaminho e beneficiados, acondicionados em sacos de juta.

A avaliação do atributo corpo apresentado em forma de freqüência, para os diferentes tipos de acondicionamentos encontram-se na Figura 5.

$\mathrm{Na}$ Figura 5, pode-se verificar a freqüência para o atributo corpo médio que, com pequenas variações, predominou em todos os tipos de acondicionamentos. No entanto, o corpo forte foi observado com maior frequiência no café com pergaminho e beneficiado, acondicionado em sacos de juta e sacos de juta com casca moída, respectivamente. Não foi observada ocorrência para o atributo corpo forte no café com e sem pergaminho, acondicionado em sacos de náilon com $\mathrm{CO}_{2}$. Verifica-se, ainda, no mesmo gráfico, que o corpo fraco não foi observado nos cafés acondicionados em sacos juta e náilon com $\mathrm{CO}_{2}$.

Pela Tabela 2, observa-se que o tipo, de maneira geral, não foi alterado durante o armazenamento, uma vez que, do início aos 360 dias de duração do experimento, predominou o tipo 5 (cinco).

Diversos autores observaram que a composição química e a classificação da bebida do café dependem do número de defeitos presentes na amostra (AMORIM, 1978; CHAGAS, 2003; MYA et al., 1973/74; PEREIRA, 1997). No presente trabalho, foi observada variação significativa na qualidade do café, em função do modo de acondicionamento ao longo do armazenamento sem, contudo, encontrar-se a correspondente alteração no tipo do café. Dessa forma podese afirmar que tais variações de qualidade do café tiveram outras causas, diversas mesmo daquelas em razão da presença de defeitos na amostra, sugerindo novos estudos para elucidar tais fatos.

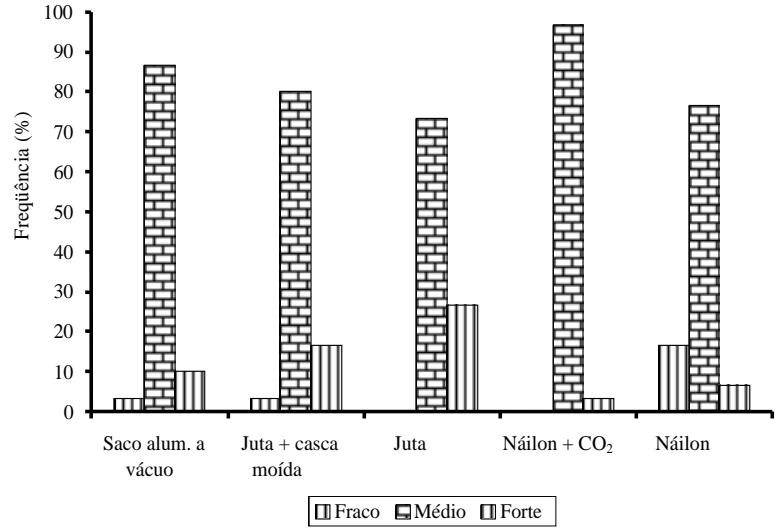

Figura 5 - Freqüência para o atributo corpo, para os diferentes tipos de acondicionamentos, em cafés com pergaminho e beneficiado.

\section{CONCLUSÕES}

Os cafés acondicionados em saco de juta e juta com casca moída apresentaram maior freqüência da bebida dura, a partir dos 180 dias de armazenamento.

Os cafés acondicionados em náilon e náilon com $\mathrm{CO}_{2}$ apresentaram maior freqüência de bebida apenas mole e mole.

Os cafés acondicionados a vácuo com e sem beneficiamento, apresentaram maior frequiência de bebida apenas mole e mole, respectivamente.

As freqüências dos atributos doçura, acidez e corpo predominaram na gradação intermediária, para todos os acondicionamentos.

O tipo não foi alterado durante o armazenamento.

Tabela 2 - Classificação do café por tipo.

\begin{tabular}{ccccccc}
\hline \multirow{2}{*}{ Tempo } & & \multicolumn{3}{c}{ Acondicionamentos } \\
\cline { 3 - 6 } & Beneficiamento & Juta & $\begin{array}{c}\text { Juta com casca } \\
\text { moída }\end{array}$ & $\begin{array}{c}\text { Sacos aluminizados } \\
\text { vácuo }\end{array}$ & Náilon & \multicolumn{2}{c}{$\begin{array}{c}\text { Náilon com } \\
\text { CO }_{2}\end{array}$} \\
\cline { 3 - 7 } 0 & Com & 5 & 5 & 5 & 5 & 5 \\
& Sem & 5 & 5 & 5 & 5 & 5 \\
\hline 90 & Com & 5 & 6 & 5 & 5 & 6 \\
& Sem & 5 & 5 & 5 & 5 & 5 \\
\hline \multirow{2}{*}{180} & Com & 5 & 5 & 5 & 5 & 5 \\
& Sem & 5 & 5 & 5 & 6 & 5 \\
\hline 30 & Com & 6 & 5 & 5 & 5 & 5 \\
& Sem & 5 & 5 & 6 & 5 & 5 \\
\hline
\end{tabular}

Ciênc. agrotec., Lavras, v. 32, n. 6, p. 1724-1729, nov./dez., 2008 


\section{REFERÊNCIAS BIBLIOGRÁFICAS}

ALVES, W. M.; FARONI, L. R.; CORREA, P. C.; PARIZZI, F. C.; PIMENTEL, M. A. Influência do processamento e do período de armazenamento na perda de matéria seca em café (Coffea arabica L.) beneficiado. Revista Brasileira de Armazenamento, Viçosa, n. 7, p. 122-127, jul. 2003. Edição especial.

AMORIM, H. V. Aspectos bioquímicos e histoquímicos do grão de café verde, relacionados com a deterioração de qualidade. 1978. 85 f. Dissertação (Livre Docência) - Escola Superior de Agricultura Luiz de Queiroz, Piracicaba, 1978.

CEREDA, M. P. Embalagens e sua utilização em produtos agropecuários. In: CEREDA, M. P.; SANCHES, S. L. Manual de armazenamento e embalagens de produtos agropecuários. Botucatu: Fundação de Estudos e Pesquisas Agrícolas e Florestais, 1983. p. 35-67.

CHAGAS, S. J. de R. Potencial da região sul de Minas Gerais para a produção de café especiais. 2003. 91 p. Tese (Doutorado em Ciência dos Alimentos) - Universidade Federal de Lavras, Lavras, 2003.

CHITARRA, M. I. F.; CHITARRA, A. B. Pós-colheita de frutas e hortaliças: fisiologia e manuseio. Lavras: ESAL/ FAEPE, 1990. 320 p.

COELHO, K. F.; PEREIRA, R. G. F. A.; VILELLA, E. R. Qualidade do café beneficiado em função do tempo de armazenamento e de diferentes tipos de embalagens. Revista Brasileira de Armazenamento, Viçosa, n. 2, p. 2227, 2001. Edição especial.

DILLEY, D. R The hypobaric concept for controlled atmosphere storage. In: Controlled atmospheres and transport of perishable agricultural commodities. Michigan: Michigan State University, 1977. p. 29-37.

GODINHO, R. P.; VILELA, E. R.; OLIVEIRA, G. A.; CHAGAS, S. J. R. Variações naco rena composição química do café (Coffea arabica L.) armazenado em côco e beneficiado. Revista Brasileira de Armazenamento, Viçosa, n. 1, p. 38-43, 2000. Edição especial.
LOPES, R. P.; HARA, T.; SILVA, J. de S.; RIEDEL, S. B. Efeito da luz na qualidade de café beneficiados (Coffea arábica L.) durante a armazenagem. Revista Brasileira de Armazenamento, Viçosa, n. 1, p. 9-17, 2001. Edição especial.

MIYA, E. E.; GARRUTI, R. S.; CHAIB, M. A.; ANGELUCCI, E.; FIGUEIREDO, I.; SHIROSE, L. Defeitos do café e qualidade da bebida. Coletânea do Instituto de Tecnologia de Alimentos, Campinas, v. 5, p. 417-432, 1973/74.

MOURA, M. L. Efeito de níveis de 02 e de $\mathrm{CO}_{2}$ na conservação pós-colheita de tomate (Licopersicum sculentum) cv. Agriset colhido em estádio intermediário de maturação. 1997. 62 f. Dissertação (Mestrado em Ciências) - Escola Superior de Agricultura Luiz de Queiroz, Piracicaba, 1997.

PASSOS, R. B. Efeito de dois tipos de embalagens a vácuo e de um monoglicerídeo acetilado (DFG) na microbiota deterioradora e patogênica da carne bovina armazenada sob refrigeração. 1991. 128 f. Dissertação (Mestrado em Ciências de Alimentos) - Universidade de Campinas, Campinas, 1991.

PENTEADO, S. R. Uso de atmosfera modificada e embalagens ativas, na conservação de figo "Roxo de Valinho" (Ficus carica L.). 1998. 100 f. Tese (Doutorado) - Escola Superior de Agricultura Luiz de Queiroz, Piracicaba, 1998.

PEREIRA, R. G. F. A. Efeito da inclusão de grãos defeituosos na composição química e qualidade do café "estritamente mole". 1997. 94 f. Tese (Doutorado) - Universidade Federal de Lavras, Lavras, 1997.

ROSSIGNOLI, P. A. Atmosfera modificada por filmes de polietileno de baixa densidade com diferentes espessuras para conservação da banana prata em condições ambientes. 1983. Dissertação (Mestrado) - Universidade Federal de Lavras, Lavras, 1983.

VILELA, E. R.; CHANDRA, P. K.; OLIVEIRA, G. A. Efeito da temperatura e umidade relativa no branqueamento de grãos de café. Revista Brasileira de Armazenamento, Viçosa, n. 1, p. 31-37, 2000. Edição especial. 